\title{
TIME CONTROL CHARTS THROUGH NHPP BASED ON DAGUM DISTRIBUTION
}

\author{
B. SRINIVASA RAO ${ }^{1, *}$, P. SRICHARANI ${ }^{2}$ \\ ${ }^{1}$ Department of Mathematics $\mathcal{E}$ Humanities, R.V.R \& J.C College of Engineering, Chowdavaram, Guntur- \\ 522 019, Andhra Pradesh, India \\ ${ }^{2}$ Department of Basic Sciences, Sri Vishnu Engineering College for Women, Bhimavaram, Andhra \\ Pradesh, India \\ *Corresponding author: boyapatisrinu@yahoo.com
}

\begin{abstract}
Statistical process control is a method of monitoring product in its development process using statistical techniques with the presumption that the products produced under identical process condition shall not always be alike with respect to some quality characteristic(s). However, if the observed variations are within the tolerable limits statistical process control (SPC) methods would pass them for acceptance. This philosophy is adopted to decide the reliability and quality of a product by defining some quality measures and proposing a probability model for the quality measurements. The well known Dagum distribution(DD) is considered to propose a product reliability based on non-homogenous Poisson process (NHPP). Its mean value function is taken as a quality characteristic and SPC limits for it are developed. These control limits are exemplified to a live failure data to detect the out of control signals for the quality of the product based on the failure data and compared with Exponential distribution(ED).
\end{abstract}

\section{Introduction}

Life time data generally contain the failure times of sample products or interfailure times or number of failures experienced in a given time. Assuming a suitable probability model the reliability of the product

Received 2017-07-31; accepted 2017-10-09; published 2018-05-02.

2010 Mathematics Subject Classification. 60K35.

Key words and phrases. Dagum distribution; exponential distribution; statistical process control; non-homogenous Poisson process.

(C) 2018 Authors retain the copyrights of their papers, and all open access articles are distributed under the terms of the Creative Commons Attribution License. 
is computed and the quality with respect to reliability would be assessed. From a different point of view if the specific life time data contain, times between failures, also called inter failure times, probability limits for such a data can be constructed in a parametric approach. Taking central line at the median of the distribution of the data, the probability limits as usual control limits we can think of a control chart for the data. Points above the upper control limit of such a data would be an encouraging characteristic of the product because they lead to a large gap between successive failures so that the uptime of the product is large. Hence the product is preferable. That is detection of out of control above the UCL is desirable and its causes are to preserved or encouraged. Similarly detection of out of control below the LCL results in shorter gaps between successive failures. The assignable causes for this detection are to be minimized or eliminated. Points within the control limits indicate a smooth failure phenomenon. Thus such a set of control limits would be helpful in assessing the quality of the product based on inter failure time data. Any manufactured product is prone to failures for known or unknown reasons. A failed product can be rectified to bring it back to functioning through a testing process. In this procedure the data of observed product failures would throw some light on the quality of the product. There are various methods of measuring the product quality and the most popular among them is product reliability. Non homogenous Poisson processes are suitable models to compute product reliability in the statistical science. The earliest works in this direction can be attributed to those of Chan et al(2000) [1], Xie et al(2002) [4], Pham and Zhang(2003) [3] and Kim(2013) [2]. All these attempts are focussed on the mathematical model of the type

$$
\mathrm{P}(\mathrm{N}(\mathrm{t}+\mathrm{s})-\mathrm{N}(\mathrm{t})=\mathrm{y})=\frac{\mathrm{e}^{-\lambda \mathrm{s}}(\lambda \mathrm{s})^{\mathrm{y}}}{\mathrm{y} !}, \mathrm{y}=0,1,2, \ldots
$$

where $N(t)$ indicates the random number of occurrences of an event in the interval $[0, t]$. This mathematical model indicates that the changes in $N(t)$ from one time period to another time period say $[t, t+s]$ depend only on the length of the interval $s$ but not on the extremities $t, t+s$ of the interval. $\lambda$ is called the failure intensity. In the above equation $E[N(t)]=\lambda t, \forall t$. If we think of a Poisson process whose mean depends on the starting $t$ and also the length of the interval $s$ such a Poisson process can be explained by an equation as

$$
\mathrm{P}(\mathrm{N}(\mathrm{t})=\mathrm{y})=\frac{\mathrm{e}^{-\mathrm{m}(\mathrm{t})}(\mathrm{m}(\mathrm{t}))^{\mathrm{y}}}{\mathrm{y} !}, \mathrm{y}=0,1,2, \ldots
$$

In this equation $m(t)$ is a positive valued, non decreasing, continuous function and is called the mean value function. Equation (1.2) is called a Non Homogenous Poisson Process. If a product system when put to use fails with probability $F(t)$ before time $t$, if ' $\theta$ ' stands for the unknown eventual number of failures that it is likely to experience, then the average number of failures expected to be experienced before time $t$ is $\theta F(t)$. Hence $\theta F(t)$ can be taken as the mean value function of an NHPP. In the theory of probability, $F(t)$ is called the cumulative distribution function $(\mathrm{CDF})$ of a continuous non negative valued random variable. Thus an NHPP designed to study the failure process of a product can be constructed as a Poisson process with 
mean value function based on the cumulative distribution function of a continuous positive valued random variable.

With this backdrop, we consider the well known Dagum distribution (DD) as F(t) to generate a growth model based Non Homogenous Poisson Process (NHPP). For such a model we developed the statistically admissible control limits for the mean value function and demonstrate the same how a graphical procedure called a statistical process control (SPC) chart based on the mean value function would help in detecting out of control signals for the product quality. The rest of the paper is organized as follows:

The basic distribution characteristics of Dagum distribution (DD)and its properties are presented in section 2. Control chart monitoring the time between failures based on the mean value function, statistically tolerable limits for the failure time random variable, comparison with Exponential model and findings are given in section 3. Monitoring the production process based on the mean value function using order statistics,

comparison with Exponential model and the findings are given in section 4. Summary and Conclusions are given in section 5 .

\section{Distribution and its properties}

In the present paper we consider the CDF of DD as the genesis of mean value function of our SQC. This model is an increasing failure rate (IFR). Such a distribution is proved to be having a number of important applications in survival analysis, a proxy concept to reliability theory.

The probability density function (pdf) of Dagum distribution is given by

$$
f(x)=\frac{a p}{x}\left(\frac{\left(\frac{x}{b}\right)^{a p}}{\left(\left(\frac{x}{b}\right)^{a}+1\right)^{p+1}}\right), x>0, a>0, b>0, p>0 .
$$

Its cumulative distribution function (cdf) is

$$
F(x)=\left(1+\left(\frac{x}{b}\right)^{-a}\right)^{-p}, x>0, a>0, b>0, p>0 .
$$

The Dagum distribution is a skewed, unimodal distribution on the positive real line. The mean, median and variance of Dagum distbution are respectively

$$
\begin{gathered}
\text { Mean }=-\frac{b}{a} \frac{\Gamma\left(-\frac{1}{a}\right) \Gamma\left(\frac{1}{a}+p\right)}{\Gamma(p)}, \text { if } a>1 . \\
\text { Median }=b\left(-1+2^{\frac{1}{p}}\right)^{-\frac{1}{a}} \cdot \\
\text { Variance }=-\frac{b^{2}}{a^{2}}\left(2 a \frac{\Gamma\left(-\frac{2}{a}\right) \Gamma\left(\frac{2}{a}+p\right)}{\Gamma(p)}+\left(\frac{\Gamma\left(-\frac{1}{a}\right) \Gamma\left(\frac{1}{a}+p\right)}{\Gamma(p)}\right)^{2}\right), \text { if } a>2 .
\end{gathered}
$$

The NHPP with $\theta \mathrm{F}(\mathrm{x})$ as the mean value function for our present study is

$$
m(x)=\theta\left(1+\left(\frac{x}{b}\right)^{-a}\right)^{-p}, \theta>0, a>0, b>0, p>0 .
$$


Thus our proposed model contains 3 parameters namely $\theta$, a and $\mathrm{b}$, where $\theta$ stands for the unknown number of faults present in the product

\section{Control chart monitoring the time between failures based on mean value function}

Let $\mathrm{F}(\mathrm{x})$ be the cumulative distribution function of a continuous positive valued random variable, $\mathrm{f}(\mathrm{x})$ be its probability density function. If the random variable is taken as representing inter failure time of a device, a control chart of such data would be based on 0.9973 probability limits of the times between failure random variable say $t$ analogous to the Shewhart's theory of variable control charts. These limits and the central line are respectively the solutions of the following equations taking equi-tailed probabilities.

$$
\begin{gathered}
F(t)=0.00135 \\
F(t)=0.5 \\
F(t)=0.99865
\end{gathered}
$$

Let $t_{U}, t_{C}$ and $t_{L}$ be respectively the solutions of equations (3.1), (3.2) and (3.3) in the standard form

$$
\begin{gathered}
t_{L}=F^{-1}(0.00135) \\
t_{C}=F^{-1}(0.5) \\
t_{U}=F^{-1}(0.99865)
\end{gathered}
$$

The NHPP with $\mathrm{F}(\theta, \mathrm{x})$ as the mean value function for our present study is

$$
m(x)=\theta\left(1+\left(\frac{x}{b}\right)^{-a}\right)^{-p}, \theta>0, a>0, b>0, p>0 .
$$

The time control chart based on the mean value function corresponding to inter failure time together with three parallel lines to the horizontal axis at $t_{L}, t_{C}$ and $t_{U}$ for the data of $\operatorname{Kim}(2013)$ [2] is given below.

Estimated values of $\mathrm{m}(\mathrm{t})$ at the given failure times $t_{1}, t_{2}, . . t_{n}$ along with the successive differences of these estimates are given in Table 3. The successive differences would indicate the estimated number of failures between consecutive failure times. The graph through $\left[t_{i}, \triangle \hat{m}\left(t_{i}\right)\right] \mathrm{i}=1,2, . ., \mathrm{n}-1$ along with three parallel horizontal lines at $m\left(t_{L}\right), m\left(t_{C}\right), m\left(t_{U}\right)$ would be the required control chart and is given in Figure 1. 
Fig 1. Control chart based on successive differences of mean value function of DD

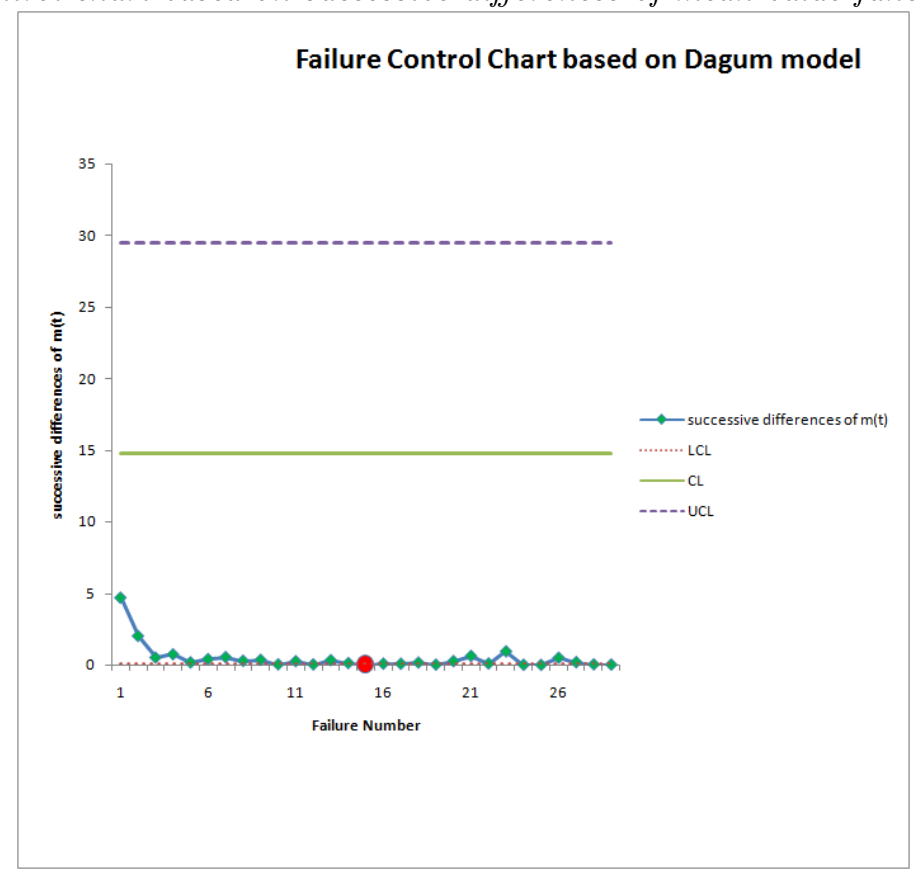

\subsection{Comparative study.}

For comparison, we take Exponential model, the most frequently used model in reliability studies. The cumulative distribution function of Exponential distribution(ED)is

$$
F(x)=1-e^{-b x}, x>0, b>0 .
$$

The NHPP with $\theta \mathrm{F}(\mathrm{x})$ as the mean value function for our present study is

$$
m(x)=\theta\left[1-e^{-b x}\right], x>0, \theta>0, b>0 .
$$

TABLE 1. Failure time data

\begin{tabular}{|c|c|c|c|c|c|}
\hline $\begin{array}{c}\text { Failure } \\
\text { number }\end{array}$ & $\begin{array}{c}\text { Failure time } \\
\text { (hours) }\end{array}$ & $\begin{array}{r}\text { Failure } \\
\text { number }\end{array}$ & $\begin{array}{c}\text { Failure time } \\
\text { (hours) }\end{array}$ & $\begin{array}{c}\text { Failure } \\
\text { number }\end{array}$ & $\begin{array}{c}\text { Failure time } \\
\text { (hours) }\end{array}$ \\
\hline 1 & 9 & 11 & 71 & 21 & 116 \\
2 & 21 & 12 & 77 & 22 & 149 \\
3 & 32 & 13 & 78 & 23 & 156 \\
4 & 36 & 14 & 87 & 24 & 247 \\
5 & 43 & 15 & 91 & 25 & 249 \\
6 & 45 & 16 & 92 & 26 & 250 \\
7 & 50 & 17 & 95 & 27 & 337 \\
8 & 58 & 18 & 98 & 28 & 384 \\
9 & 63 & 19 & 104 & 29 & 396 \\
10 & 70 & 20 & 105 & 30 & 405 \\
\hline
\end{tabular}


TABle 2. Parameter estimates of Dagum distribution and their control limits

\begin{tabular}{|c|c|c|c|c|c|c|}
\hline \multicolumn{7}{|c|}{ Dagum model } \\
\hline $\mathrm{a}$ & $\mathrm{b}$ & $\mathrm{p}$ & $\hat{\theta}$ & $m\left(t_{L}\right)$ & $m\left(t_{C}\right)$ & $m\left(t_{U}\right)$ \\
\hline 0.6 & 0.5 & 5 & 29.47 & 0.0398 & 14.7349 & 29.4302 \\
\hline
\end{tabular}

TABLE 3. Successive differences based on the mean value function of DD

\begin{tabular}{|c|c|c|c|c|c|c|c|}
\hline Failure & $\begin{array}{c}\text { Failure time } \\
\text { number }\end{array}$ & $\mathrm{m}(\mathrm{t})$ & $\begin{array}{c}\text { Successive } \\
\text { differences of } \mathrm{m}(\mathrm{t})\end{array}$ & $\begin{array}{c}\text { Failure } \\
\text { number }\end{array}$ & $\begin{array}{c}\text { Failure time } \\
\text { (hours })\end{array}$ & $\mathrm{m}(\mathrm{t})$ & $\begin{array}{c}\text { Successive } \\
\text { differences of } \mathrm{m}(\mathrm{t}) \\
1\end{array}$ \\
\hline 2 & 21 & 17.7929 & 2.036 & 17 & 95 & 23.8839 & 0.091 \\
3 & 32 & 19.829 & 0.524 & 18 & 98 & 23.9751 & 0.17 \\
4 & 36 & 20.352 & 0.75 & 19 & 104 & 24.1455 & 0.027 \\
5 & 43 & 21.103 & 0.184 & 20 & 105 & 24.1725 & 0.274 \\
6 & 45 & 21.287 & 0.415 & 21 & 116 & 24.4469 & 0.635 \\
7 & 50 & 21.702 & 0.557 & 22 & 149 & 25.0821 & 0.108 \\
8 & 58 & 22.261 & 0.296 & 23 & 156 & 25.1904 & 0.959 \\
9 & 63 & 22.556 & 0.363 & 24 & 247 & 26.1494 & 0.015 \\
10 & 70 & 22.919 & 0.048 & 25 & 249 & 26.1643 & 0.007 \\
11 & 71 & 22.967 & 0.267 & 26 & 250 & 26.1717 & 0.509 \\
12 & 77 & 23.234 & 0.042 & 27 & 337 & 26.6811 & 0.199 \\
13 & 78 & 23.276 & 0.343 & 28 & 384 & 26.8799 & 0.045 \\
15 & 87 & 23.619 & 0.137 & 29 & 396 & 26.9248 & 0.032 \\
\hline
\end{tabular}

TABLE 4. Parameter estimates of Exponential model and their control limits

\begin{tabular}{|c|c|c|c|c|}
\hline \multicolumn{5}{|c|}{ Exponential model } \\
\hline $\mathrm{b}$ & $\hat{\theta}$ & $m\left(t_{L}\right)$ & $m\left(t_{C}\right)$ & $m\left(t_{U}\right)$ \\
\hline 0.03 & 30.00016 & 0.0405 & 15.0008 & 29.9596 \\
\hline
\end{tabular}


TABLE 5. Successive differences based on the mean value function of ED

\begin{tabular}{|c|c|c|c|c|c|c|c|}
\hline $\begin{array}{l}\text { Failure } \\
\text { number }\end{array}$ & $\begin{array}{c}\text { Failure time } \\
\text { (hours) }\end{array}$ & $\mathrm{m}(\mathrm{t})$ & $\begin{array}{c}\text { Successive } \\
\text { differences of } \mathrm{m}(\mathrm{t}) \\
\triangle \hat{m}(t)\end{array}$ & $\begin{array}{l}\text { Failure } \\
\text { number }\end{array}$ & $\begin{array}{c}\text { Failure time } \\
\text { (hours) }\end{array}$ & $\mathrm{m}(\mathrm{t})$ & $\begin{array}{c}\text { Successive } \\
\text { differences of } \mathrm{m}(\mathrm{t}) \\
\triangle \hat{m}(t)\end{array}$ \\
\hline 1 & 9 & 7.09865 & 6.924 & 16 & 92 & 28.1014 & 0.163 \\
\hline 2 & 21 & 14.0223 & 4.491 & 17 & 95 & 28.2648 & 0.149 \\
\hline 3 & 32 & 18.5133 & 1.299 & 18 & 98 & 28.4142 & 0.261 \\
\hline 4 & 36 & 19.8122 & 1.93 & 19 & 104 & 28.6754 & 0.039 \\
\hline 5 & 43 & 21.742 & 0.481 & 20 & 105 & 28.7146 & 0.361 \\
\hline 6 & 45 & 22.2229 & 1.083 & 21 & 116 & 29.0759 & 0.581 \\
\hline 7 & 50 & 23.7345 & 1.428 & 22 & 149 & 29.6567 & 0.065 \\
\hline 8 & 58 & 24.7345 & 0.733 & 23 & 156 & 29.7218 & 0.26 \\
\hline 9 & 63 & 25.468 & 0.858 & 24 & 247 & 29.982 & 0.001 \\
\hline 10 & 70 & 26.3264 & 0.109 & 25 & 249 & 29.2831 & 0.0005 \\
\hline 11 & 71 & 26.435 & 0.587 & 26 & 250 & 29.9836 & 0.0153 \\
\hline 12 & 77 & 27.0223 & 0.088 & 27 & 337 & 29.9989 & 0.00009 \\
\hline 13 & 78 & 27.1103 & 0.684 & 28 & 384 & 29.9999 & 0.000009 \\
\hline 14 & 87 & 27.7941 & 0.249 & 29 & 396 & 30 & 0.000005 \\
\hline 15 & 91 & 28.0436 & 0.058 & 30 & 405 & 30 & \\
\hline
\end{tabular}

Fig 2. Control chart based on successive differences of mean value function of ED

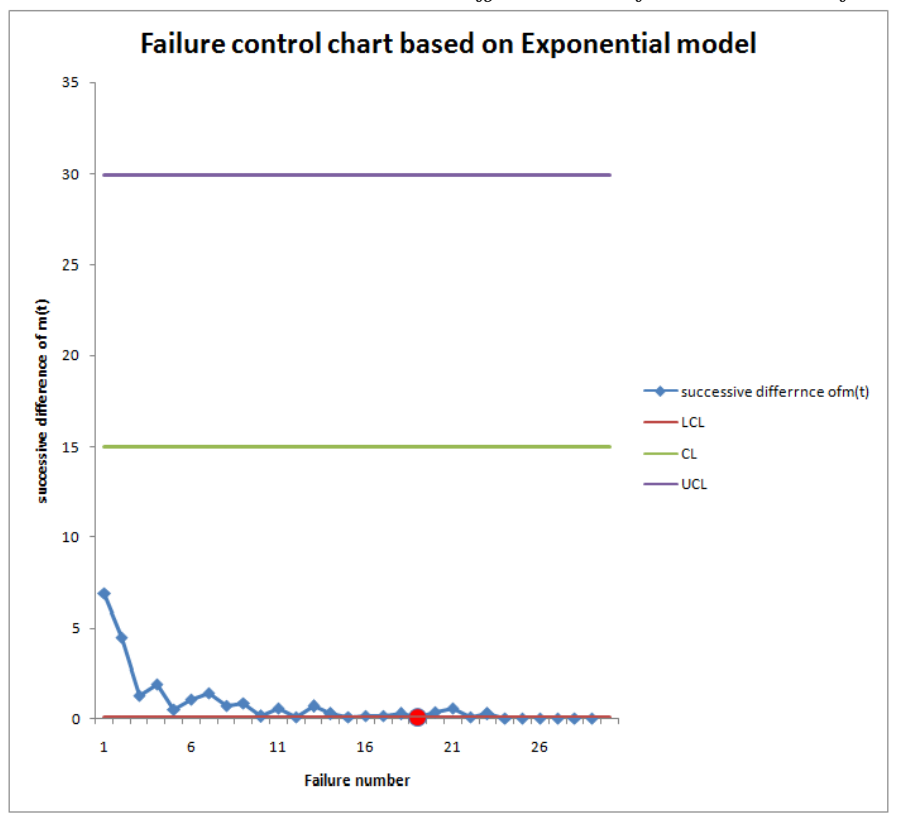




\section{Monitoring the production process based on mean value function using order statistics}

Let $x_{1}, x_{2}, . ., x_{n}$ be a random sample of size $n$ representing $\mathrm{n}$ inter failure times of a product governed by the probability model of a continuous random variable $\mathrm{X}$. Let $\mathrm{F}(\mathrm{x})$ be the cumulative distribution function of X. These inter failure times can be used for assessing the failure phenomenon with respect to two limits of reference called control limits with a pre specified coverage probability. Thus the time control chart plotted for inter failure times would indicate alarms, advantages and stable failure process. If $\mathrm{r}$ is a natural number

$(<\mathrm{n})$, the summations $\sum_{i=1}^{r} X_{i}, \sum_{i=r+1}^{2 r} X_{i}, \sum_{i=2 r+1}^{3 r} X_{i}$ etc represent the lapse of time consecutively between every $r^{\text {th }}$ failure. A control chart for times between every $r^{\text {th }}$ failure would throw light on the out of control signals than that of inter failure times. Xie et al(2002) [4] named such a control chart as $t_{r}$-control chart and developed control limits using the sampling distribution of $\sum_{i=1}^{r} X_{i}$. They have taken the example of exponential distribution and used the theory that the sum of exponential variates is a gamma variate to get the percentiles of $t_{r}$-control chart with the help of cumulative summations. If the inter failure times are not exponentials, the control limits of $t_{r}$-chart of Xie et al(2002) [4] can not be used.

Overcoming this drawback we suggest the following alternative approach to get control limits of $t_{r}$-chart for Dagum distribution. If $\left(X_{1}, X_{2}, . ., X_{r}\right) ;\left(X_{r+1}, X_{r+2}, . ., X_{2 r}\right) ;\left(X_{2 r+1}, X_{2 r+2}, . ., X_{3 r}\right)$; etc are regarded as independent samples of size $\mathrm{r}$ each, i.i.d random variables having $\mathrm{F}(\mathrm{x})$ as their common model. $Y_{1}=X_{1}$, $Y_{2}=\sum_{i=1}^{2} X_{i}, Y_{3}=\sum_{i=1}^{3} X_{i}, \ldots . ., Y_{r}=\sum_{i=1}^{r} X_{i}$ becomes an ordered sample of size $r$ representing the time to first failure, time to second failure, time to third failure,....., time to $r^{t h}$ failure respectively. Thus, the $t_{r}$-chart is the control chart with $Y_{r}$ as the points on it representing the time to every $r^{\text {th }}$ failure. Therefore, when $r$ is fixed, the percentiles of highest order statistics in a sample of size $r$ would serve the purpose of control limits for the $t_{r}$-chart.

Let $\mathrm{F}(\mathrm{x})$ be the cumulative distribution function of a continuous positive valued random variable. If the random variable is taken as representing inter failure time of a device, a control chart of such data with order statistics would be based on 0.9973 probability limits of the times between failure random variable say $t$. These limits and the central line are respectively the solutions of the following equations taking equi-tailed probabilities.

$$
\begin{gathered}
{[F(t)]^{r}=0.00135} \\
{[F(t)]^{r}=0.5} \\
{[F(t)]^{r}=0.99865}
\end{gathered}
$$

Let $t_{U}, t_{C}$ and $t_{L}$ be respectively the solutions of equations (3.1), (3.2) and (3.3) in the standard form

$$
t_{L}=F^{-1}\left(0.00135^{\frac{1}{r}}\right)
$$




$$
\begin{gathered}
t_{C}=F^{-1}\left(0.5^{\frac{1}{r}}\right) \\
t_{U}=F^{-1}\left(0.99865^{\frac{1}{r}}\right)
\end{gathered}
$$

The NHPP with $\theta . \mathrm{F}(\mathrm{x})$ as the mean value function for our present study is

$$
m(x)=\theta\left(1+\left(\frac{x}{b}\right)^{-a}\right)^{-p}, \theta>0, a>0, b>0, p>0 .
$$

The above model is illustrated for the example of 60 failure times considered by Xie et al(2002) [4]. For a ready reference the data is produced in table 6 .

TABLE 6. Failure time data of the components

\begin{tabular}{|c|c|c|c|c|c|c|c|}
\hline $\begin{array}{c}\text { Failure } \\
\text { number }\end{array}$ & Time & $\begin{array}{c}\text { Failure } \\
\text { number }\end{array}$ & Time & $\begin{array}{c}\text { Failure } \\
\text { number }\end{array}$ & Time & $\begin{array}{c}\text { Failure } \\
\text { number }\end{array}$ & Time \\
\hline 1 & 1065.55 & 16 & 2932.96 & 31 & 35.85 & 46 & 239.66 \\
2 & 535.8 & 17 & 987.67 & 32 & 362.8 & 47 & 93.78 \\
3 & 540.53 & 18 & 1816.18 & 33 & 357.85 & 48 & 680.45 \\
4 & 716.2 & 19 & 117.21 & 34 & 334.48 & 49 & 4.83 \\
5 & 2525.43 & 20 & 190.65 & 35 & 80.13 & 50 & 102.91 \\
6 & 1264.18 & 21 & 943.99 & 36 & 1939.0 & 51 & 479.05 \\
7 & 479.44 & 22 & 1084.48 & 37 & 77.88 & 52 & 156.67 \\
8 & 1783.22 & 23 & 2306.54 & 38 & 4.03 & 53 & 1286.24 \\
9 & 473.67 & 24 & 6.56 & 39 & 98.67 & 54 & 443.97 \\
10 & 2265.42 & 25 & 3111.51 & 40 & 17.19 & 55 & 360.03 \\
11 & 2191.75 & 26 & 283.86 & 41 & 289.79 & 56 & 414.66 \\
12 & 1097.26 & 27 & 659.39 & 42 & 63.99 & 57 & 128.9 \\
13 & 597.59 & 28 & 683.48 & 43 & 2.46 & 58 & 36.1 \\
14 & 971.16 & 29 & 36.14 & 44 & 697.68 & 59 & 197.31 \\
15 & 3157.29 & 30 & 754.16 & 45 & 1167.33 & 60 & 418.12 \\
\hline
\end{tabular}


TABLE 7. Accumulation failure time for every three failures

\begin{tabular}{|c|c|c|c|}
\hline Observation & $\begin{array}{c}\text { Accumulation } \\
\text { of } 3 \text { failures }\end{array}$ & Observation & $\begin{array}{c}\text { Accumulation } \\
\text { of } 3 \text { failures }\end{array}$ \\
\hline 1 & 2141.88 & 11 & 756.5 \\
2 & 4505.81 & 12 & 2353.61 \\
3 & 2736.33 & 13 & 180.58 \\
4 & 5554.43 & 14 & 370.97 \\
5 & 4726.04 & 15 & 1867.47 \\
6 & 5736.81 & 16 & 1013.89 \\
7 & 1251.85 & 17 & 586.79 \\
8 & 3397.58 & 18 & 1886.88 \\
9 & 4054.76 & 19 & 903.59 \\
10 & 1473.78 & 20 & 651.53 \\
\hline
\end{tabular}

TABLE 8. Parameter estimates of Dagum distribution and their control limits

\begin{tabular}{|c|c|c|c|c|c|c|}
\hline \multicolumn{7}{|c|}{ Dagum model } \\
\hline $\mathrm{a}$ & $\mathrm{b}$ & $\mathrm{p}$ & $\hat{\theta}$ & $m\left(t_{L}\right)$ & $m\left(t_{C}\right)$ & $m\left(t_{U}\right)$ \\
\hline 0.8 & 0.1 & 0.5 & 20.9884 & 0.000015 & 4.7555 & 20.9278 \\
\hline
\end{tabular}

TABLE 9. Mean value function for accumulated failure times of DD

\begin{tabular}{|c|c|c|c|c|c|}
\hline Observation & $\begin{array}{c}\text { Accumulation } \\
\text { of } 3 \text { failures }\end{array}$ & $\mathrm{m}(\mathrm{t})$ & Observation & $\begin{array}{c}\text { Accumulation } \\
\text { of } 3 \text { failures }\end{array}$ & $\mathrm{m}(\mathrm{t})$ \\
\hline 1 & 2141.88 & 20.881 & 11 & 756.5 & 20.741 \\
2 & 4505.81 & 20.929 & 12 & 2353.61 & 20.888 \\
3 & 2736.33 & 20.899 & 13 & 180.58 & 20.222 \\
4 & 5554.43 & 20.938 & 14 & 370.97 & 20.554 \\
5 & 4726.04 & 20.931 & 15 & 1867.47 & 20.868 \\
6 & 5736.81 & 20.939 & 16 & 1013.89 & 20.793 \\
7 & 1251.85 & 20.823 & 17 & 586.79 & 20.686 \\
8 & 3397.58 & 20.913 & 18 & 1886.88 & 20.869 \\
9 & 4054.76 & 20.923 & 19 & 903.59 & 20.774 \\
10 & 1473.78 & 20.843 & 20 & 651.53 & 20.711 \\
\hline
\end{tabular}


Fig 3. Control chart based on accumulated failures of mean value function of DD

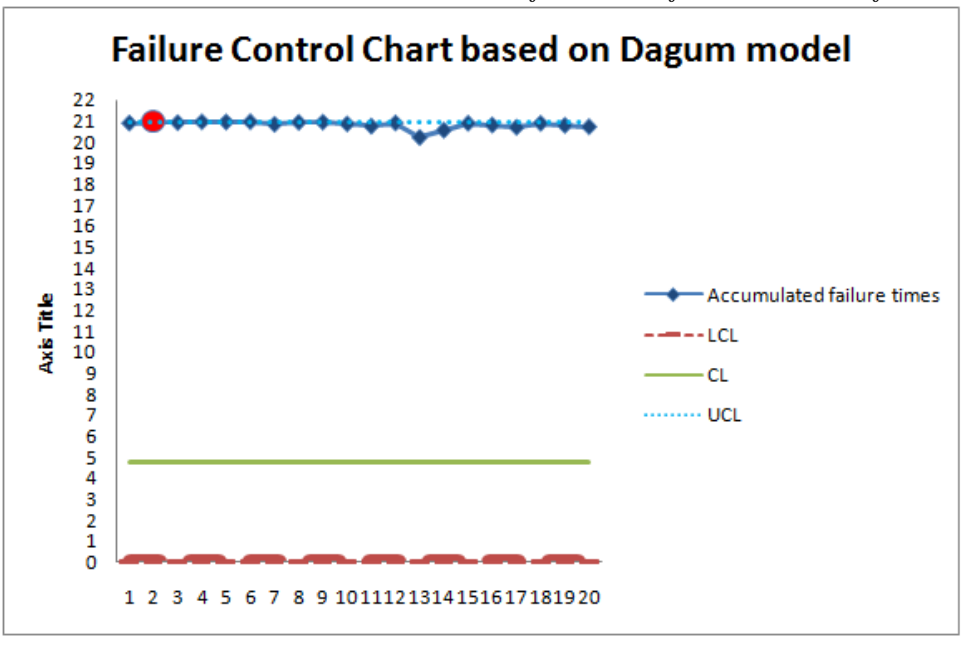

\subsection{Comparative study based on accumulated failure times.}

We compare our model under study with the exponential model using the data set given in table 6 and the results are as follows:

TABLE 10. Parameter estimates of Exponential model and their control limits

\begin{tabular}{|c|c|c|c|c|}
\hline \multicolumn{5}{|c|}{ Exponential model } \\
\hline $\mathrm{b}$ & $\hat{\theta}$ & $m\left(t_{L}\right)$ & $m\left(t_{C}\right)$ & $m\left(t_{U}\right)$ \\
\hline 0.02 & 20.00004 & 1.5023 & 13.0130 & 19.8830 \\
\hline
\end{tabular}

TABLE 11. Mean value function for accumulated failure times of ED

\begin{tabular}{|c|c|c|c|c|c|}
\hline Observation & $\begin{array}{c}\text { Accumulation } \\
\text { of } 3 \text { failures }\end{array}$ & $\mathrm{m}(\mathrm{t})$ & Observation & $\begin{array}{c}\text { Accumulation } \\
\text { of } 3 \text { failures }\end{array}$ & $\mathrm{m}(\mathrm{t})$ \\
\hline 1 & 2141.88 & 20.00004 & 11 & 756.5 & 20.00004 \\
2 & 4505.81 & 20.00004 & 12 & 2353.61 & 20.00004 \\
3 & 2736.33 & 20.00004 & 13 & 180.58 & 19.45987 \\
4 & 5554.43 & 20.00004 & 14 & 370.97 & 19.98805 \\
5 & 4726.04 & 20.00004 & 15 & 1867.47 & 20.00004 \\
6 & 5736.81 & 20.00004 & 16 & 1013.89 & 20.00004 \\
7 & 1251.85 & 20.00004 & 17 & 586.79 & 19.99988 \\
8 & 3397.58 & 20.00004 & 18 & 1886.88 & 20.00004 \\
9 & 4054.76 & 20.00004 & 19 & 903.59 & 20.00004 \\
10 & 1473.78 & 20.00004 & 20 & 651.53 & 20 \\
\hline
\end{tabular}


Fig 4. Control chart based on accumulated failures of mean value function of ED

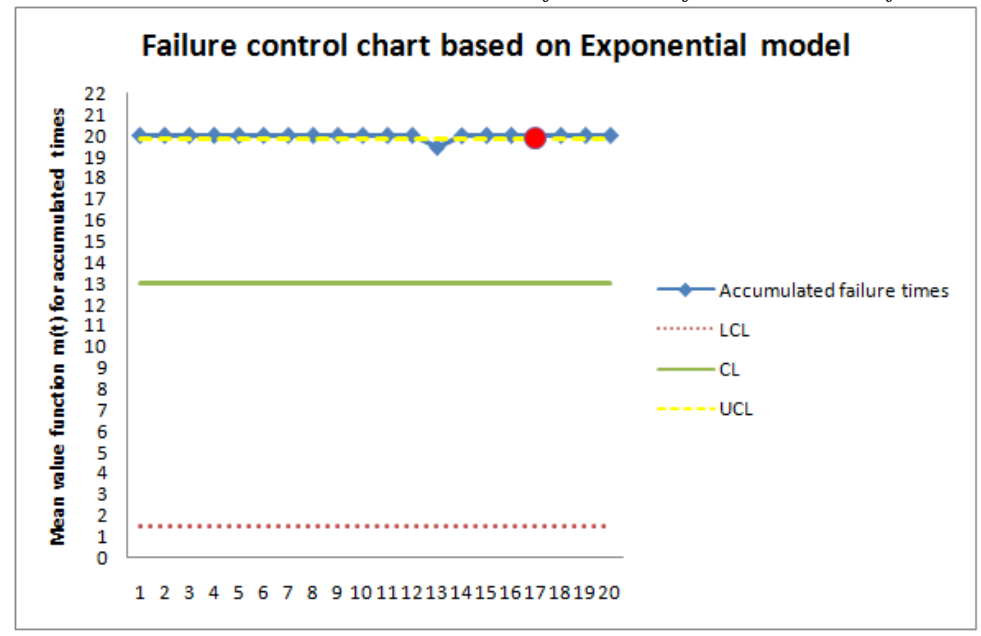

\section{Summary \& Conclusions}

In Figure 1, the first out of control situation is noticed at the $15^{\text {th }}$ failure with the corresponding successive difference of $m(t)$ falling below LCL and hence a preferable out-of-control signal for the product. Where as in Figure 2, it is noticed at $19^{\text {th }}$ failure. The earlier the failure, one can alert the process and assignable cause for this is to be investigated and can be promoted. There are many charts which use statistical techniques. It is important to use the best chart for the given data, situation and need. In the first part of the paper, the control chart for estimated number of failures in successive failure time intervals against the serial order of the failure interval is developed with the associated control lines and central line at same serial point on that of $\operatorname{Kim}(2013)[2]$.

Similarly for the control limits based on the accumulated failure times also shows that Dagum distribution is better model when compared with that of the exponential model used by Xie et al(2002) [4]. From the figure 3 and 4 we can observe that $2^{\text {nd }}$ and $19^{\text {th }}$ accumulated failure time is out of the limits respectively. The earlier the failure group, one need not to wait till the last group failure occurs.

\section{REFERENCES}

[1] Chan, L.Y., Xie, M. and Goh, T.N. Cumulative quality control charts for monitoring production process, Int. J. Product. Res., 38(2)( 2000), 397-408.

[2] Kim, H.C. Assessing software reliability based on NHPP using SPC, Int. J. Softw. Eng. Appl., 7(6)(2013), 61-70.

[3] Pham, H. and Zhang, X. Non homogeneous poisson process software reliability and cost models with testing coverage, Eur. J. Oper. Res., (145)(2003), 443-454.

[4] Xie, M., Goh, T.N. and Ranjan, P. Some effective control chart procedurs for reliability monitoring, Reliab. Eng. Syst. Safety, 77(2002), 143-150. 